\title{
Letter
}

\section{A surface electrode for laryngeal electromyography}

SIR,-By the use of a surface electrode, it is possible to record the electromyograph of the intrinsic laryngeal muscles sited behind the larynx including the important posterior crico-arytenoid muscle. Such an electrode is easily swallowed into position, enabling recordings to be made of the normal phasic breathing activity of these muscles and the abnormal muscle activity seen in denervation disorders of the larynx.

The action of the muscles of the larynx in relation to phonation and respiration has long been a subject of interest and contention. Unique amongst the airways the intrinsic and extrinsic muscles of the larynx are an integral part of the striated respiratory musculature. ${ }^{1}$ In order to record laryngeal electromyograms (LEMG), previous investigators have used various needle electrodes. These are inserted either percutaneously ${ }^{2}$ or by indirect laryngoscopy. ${ }^{3}$ Both methods require much skill to place the electrodes safely and correctly. Not only may they cause discomfort to the patient but may also provoke unwanted electromyographic artifacts.

Recently it has been shown that there are marked histological changes in the main abductor muscle of the larynx, the posterior crico-arytenoid (PCA), suggesting denervation, in patients suffering from the Shy-drager disorder (autonomic neuropathy). ${ }^{*}$ Similar findings have also been obtained in patients with chronic airflow obstruction. A new non-invasive technique for studying this muscle and its phasic activity with respiration has therefore been sought. To this end a surface electrode has been made which facilitates the recording of surface EMGs from certain laryngeal muscles including muscles of particular interest such as the posterior cricoarytenoid which lies at the back of the cricoid lamina covered by a thin layer of mucosa from the anterior wall of the hypo-pharynx.

A bipolar electrode as in fig 1 is ideal for sampling the PCA muscle as well as the higher interarytenoid which lies less than $1 \mathrm{~cm}$ above the PCA muscle. Electrodes may also be prepared to study unilateral disorders of the larynx as in recurrent laryngeal nerve lesions as well as providing simultaneous records of muscles PCA and arytenoid. Signals from the electrodes pass via isolation amplifiers with gains of 10000 and high and low pass filtering at $5 \mathrm{~Hz}$ and $1600 \mathrm{~Hz}$ respectively.

Topical anaesthesia (a $10 \% \mathrm{w} / \mathrm{v}$ lignocaine spray) is applied to fauces and pharynx. The electrode is then swallowed into position, correct positioning of the electrode being checked by fibre optic visualisation or lateral neck radiography. The respiratory cycle can be monitored either by means of flow gauge at the mouth or a thermistor at the nostril. The raw EMG, the averaged EMG (according to amplitude and frequency) for each pair of plates and the

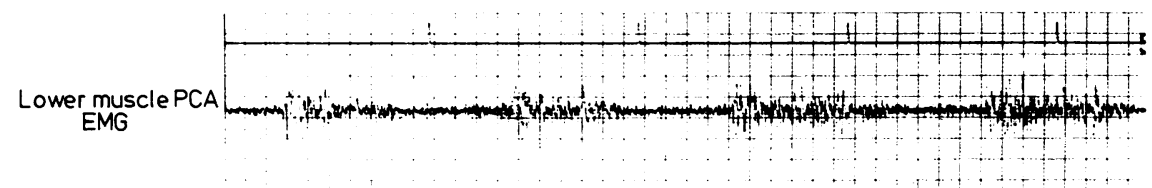

Mean EMG
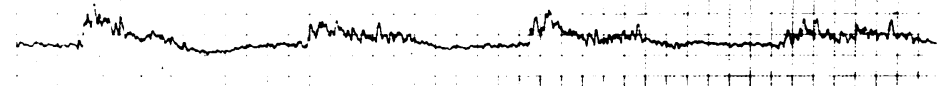

Breathing trace inspiration up
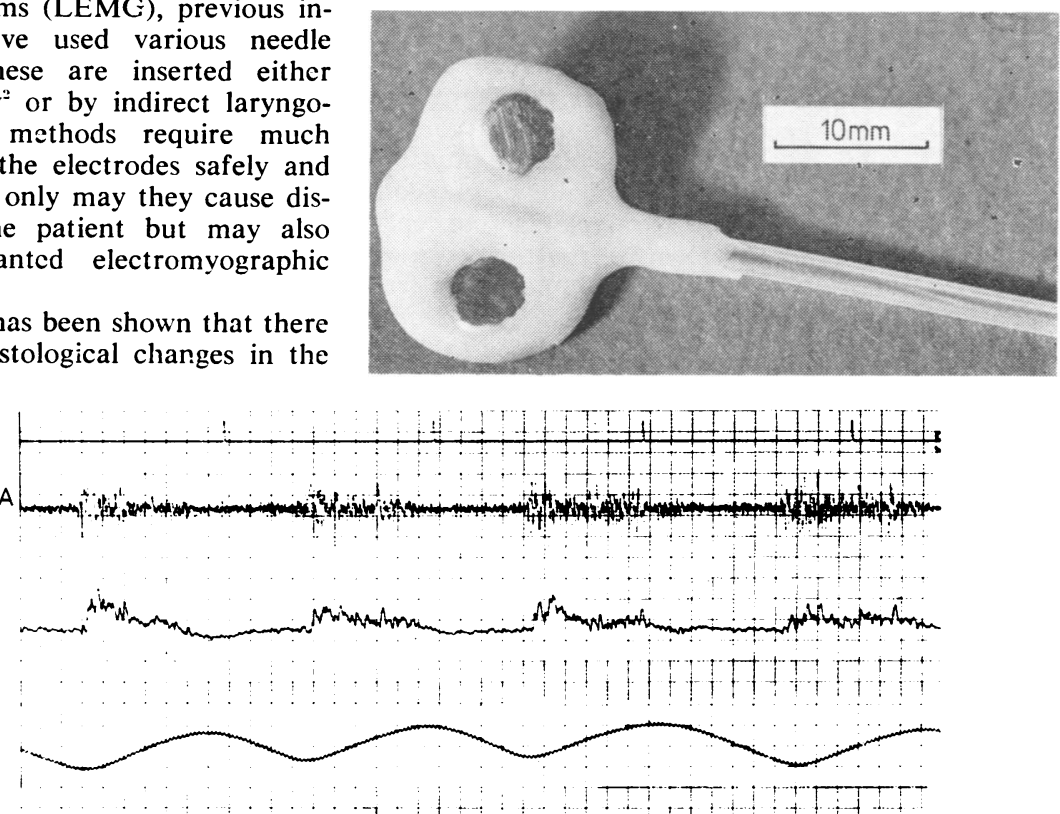

Fig 1 The bipolar electrode consists of two stainless steel plates coated in medical grade silicone rubber.

\section{Upper muscle interarytenoid EMG}

Mean EMG
Fig 2 An example of the tracing obtained using four plates, the lower two over the PCA muscle. and the upper two over the interarytenoid muscle. 
volume signal is recorded on five channels of a fast paper recorder and FM tape recorder simultaneously. An example of one such record is shown in fig 2. The phasic activity of the PCA muscle with inspiration can clearly be seen while the interarytenoid remains relatively inactive throughout the respiratory cycle, becoming active during breath holding.

The surface electrode will be of great importance in the future study of pathological states of the laryngeal musculature as well as providing information on the neurological control of the larynx.

JK PAYNE

Clinical Physics and Bioengineering, Guy's Hospital, London.

TIM HIGENBOTTAM

Guy's Hospital, London.

Royal National Throat, Nose and

GM GUINDI

Ear Hospital, London.

\section{References}

1 Campbell EJM, Agostoni E, Newsom-Davis J (1970) The respiratory muscles: Mechanics and neural control 2nd edn. London: Lloyd Luke, 1970.

2 Hiroto I, Hirano M, Toyozumi Y, Shin T. Electromyographic investigation of intrinsic laryngeal muscles related to speech sounds. Ann Otol Laryngol 1967; 76: 861-72.

3 Kotby NM, Haugen LK. Critical evaluation of the action of the P.C.A. muscle utilising direct EMG study. Acta Otolaryn 1970; 70:260-8.

4 Guindi GM, Michaels L, Bannister $\mathbf{R}$, Gibson W. Pathology of the intrinsic muscles of the larynx. Clinical Otolaryngology (in press). 1980.

\section{Book reviews}

Neuropsychology - A textbook of systems and psychological functions of the human brain by Stuart J Dimond (pp 560; £25.00) London: Butterworths 1980

This is not a textbook of neuropsychology in the sense that most clinicians would use that term. Rather it is an attempt to use neuropsycho- logical evidence to build a set of models about the way the brain controls and makes possible a wide variety of psychological functions. The range from motor behaviour and the analysis of sensory information at one extreme, through more complex functions like memory and language, to even consciousness and the concept of "self". To say the least, the scope of the book is very wide and the goals ambitious. Stuart Dimond brings to this task the fruits of an extensive knowledge of the literature and his own well-known studies of interhemispheric processing and the split-brain. The reviewer has already found the book to be a useful source of reference on some obscure points.

The inevitable problem with a book that attempts to give an overall model of many highly complex processes is that the author is forced to speculate way beyond the immediate implications of the available data. It is impossible to do this without offending many existing theoretical susceptibilities. The overall approach assumes that the higher functions can be fairly strictly localised to a degree that would make some other authorities a little unhappy. There are also enormous philosophical complications inherent in an attempt to create a neuropsychology of consciousness and related concepts. Another problem is that the use of florid descriptive terminology can irritate and confuse rather than illuminate. For example, it is stated that the arcuate fasciculus and associated structures are "a vast organ console on which the stuff of mental life can play to produce the richly orchestrated sounds of the voice as they appear in language".

Despite the criticisms, this book will no doubt be used by many as a useful starting point to examine some topics. However, it is definitely not the book for someone seeking an introduction to clinical neuropsychology. The price is very high which adds insult to certain production errors. Page 460 is missing and this is compensated for by providing two of $p$ 467. Plotting the classical speech areas onto a diagram of the right hemisphere is also not an action best designed to convince the reader that this is a sound way to invest $£ 25$.

EDGAR MILLER
Research in the Psychobiology ot Human Behaviour, edited by Eugene Meyer III and JV Brady (pp 144, £8.50\% London: Johns Hopkins Universit Press, 1979.

This little book contains seven paperso that were delivered (along with othen papers not reprinted) at the Adolf. Meyer Symposium on Psychobiology held to mark the hundredth anniversary: of the founding of Johns Hopkins University. The topics discussed include noradrenergic synaptic transmission genetics of schizophrenia, neuroendo crine research in psychiatry, psychoosomatic effects of learning, the classification of affective disorders. The authors, including Kety, Sachar and? Roth, are all experts in their own fields. They mostly write well but, as one would expect of a symposium, dow not present new material. Several of the topics have a very tenuous con nection with Adolf Meyer, who had no interest in the genetics of schizophrenia or in the classification of affective disorders. Indeed Meyer must ben some of the responsibility for neglect of these two important iss? by American academic psychiatry urifiquite recently. The book is be्fst regarded as a small collection tof interesting accounts of research irfo various aspects of the biology क्षेक्ठ psychiatry. A librarian with an unsp实 balance might just buy it.

JL GIBBONSO

Systemic Pathology Edited by W St C Symmers (pp 2522; £35) Edinburgh: Churchill Livingstone, 1979.

This is the second, greatly expanded $\frac{0}{\mathrm{D}}$ edition of this book. A separate chaptere each is devoted to the central nervous $\overrightarrow{\bar{O}}$ system, the peripheral nerves and to the 3 skeletal muscles, amounting to just over 300 pages thus bridging a gap between those popular neuropathology textbooks which always seem to have the word basic, essential or concise in theiro titles and the heavier, more detailed $\frac{\sigma}{3}$ volumes. The largest contribution is, of course, on the central nervous system; here all the major groups of diseases, including neural neoplasia, are dealto with with remarkable clarity by $\mathrm{Mc}-$ Menemey, and revised by the author and Thomas Smith. Cavanagh provides not only accurate descriptions of the $\mathrm{N}$ diseases of peripheral nerves but also an insight into basic cellular mechan- 